\title{
Social Mobility of Farsi Women Based on Economic Components in the Period of 1921 to 1953
}

Movilidad social de las mujeres farsi basadas en componentes económicos en el período de 1921 a 1953

\author{
Zainab Zomorodin ${ }^{1}$ \\ Persian Gulf University - Iran \\ zomorodin93@gmail.com \\ Ali Rasouli \\ Persian Gulf University - Iran \\ rasooli@pgu.ac.ir \\ Habibollah Saeedi $\mathrm{Nia}^{3}$ \\ Persian Gulf University - Iran \\ h_saeedinia@yahoo.com \\ Mohammad Mansouri Moghaddam ${ }^{4}$ \\ Persian Gulf University - Iran \\ mansorimoghadam@pgu.ac.ir
}

\begin{abstract}
Social mobility is one of the social science concepts to measure the degree of development and progress of a country. Some factors of social mobility such as education, job promotion, marriage, migration, etc., demonstrate the dynamics of society and the equality of status of people in the use of opportunities to obtain social benefits. The most important barriers to social mobility are the traditions and cultures of society, as well as the bureaucratic structure of government. This article seeks to show social mobility among Farsi women in the period 1921-1953. The study findings confirm that there is a wide range of vertical mobility among Farsi women during this period. The information in this study was based on libraries and documentary sources. And the method is historical research with a descriptive-analytical approach.
\end{abstract}

Keywords: Social Mobility, Economic Activity, Fars, Women.

\section{RESUMEN}

La movilidad social es uno de los conceptos de ciencias sociales para medir el grado de desarrollo y progreso de un país. Agunos factores de la movilidad social como la educación, la promoción laboral, el matrimonio, la migración, etc., demuestran la dinámica de la sociedad y la igualdad de condición de las personas en el uso de oportunidades para obtener beneficios sociales. Las barreras más importantes para la movilidad social son las tradiciones y culturas de la sociedad, así como la estructura burocrática del gobierno. El presente artículo busca mostrar la movilidad social entre las mujeres farsi en el período 19211953. Los hallazgos del estudio confirman que existe un amplio rango de movilidad vertical entre las mujeres farsi durante este período. La información en este estudio se basó en bibliotecas y fuentes documentales. Y el método es la investigación histórica con un enfoque descriptivo-analítico.

Palabras clave: movilidad social, actividad económica, Farsí, mujeres.

$1 \mathrm{PhD}$ student in the history of Islamic Iran, Persian Gulf University, Bushehr, Iran.

2 Corresponding author. Assistant Professor of History Department of Persian Gulf University, Bushehr, Iran.

3 Associate Professor of History Department of Persian Gulf University, Bushehr, Iran.

4 Assistant Professor of History Department of Persian Gulf University, Bushehr, Iran.

Recibido: 26/10/2019 Aceptado: 06/12/2019 


\section{Introduction}

At the beginning of the fourteenth century there were changes in the country. The literacy movement, industries flourished, and agricultural activities improved compared to the Qajar era, and various schools for boys and girls were established to study science and social readiness. Women who were excluded from the social and economic activities of society due to the traditional and patriarchal context of society and who were not present in the public, especially in the administrative and economic spheres, became active. Milespo about the presence of women in office in that day, Iranian society says: "They never had the opportunity to meet and talk with an Iranian woman because they had no role in the social and administrative environment in which I was living, except for a few women who served as girls' school teachers or police officers. "There is no woman in the employment of offices" (Milespo, 1977: 128). Of course, this changed with modernism, and women became very prominent in the social realm. Women have come more into the social field than ever before, and this coming out enables them to play a more active role in socio-economic trends in society, to open new schools ... to work in industries and His social presence in the health care of the country to be effective in the health of the community "(Salah, 2005: 88). Therefore, the author of this paper attempts to first define and explain social mobility and its types and then to examine the case of Farsi women in this period to determine what social mobility occurred during this period. During this time, there was significant social mobility at the level of women in the country in general and Persian women in particular, in line with the modernist policies of the time. The sources of research are library and documentary and their method is historical with a descriptive-analytical approach. First of all, there are several topics to be introduced:

A) Social mobility: The word "mobility" literally means mobility (Aryanpour, 2006: 1424). Social mobility observes changes in the status of class belonging to individuals in societies and studies the context, causes, and types of these changes. This term does not include geographical and spatial motion (Taghavi, 2010: 55). From the time of Sorokin who first seriously discussed social mobility to the present day various definitions of the concept of social mobility have been proposed. Overall, the similarities between these definitions are more than their differences, in other words, there is little difference in terms of content. In general, these definitions emphasize the position of individuals or groups and social strata in the hierarchy and social and economic structure, with the assumption that there is some kind of hierarchy in societies. However, they have used somewhat different meanings and definitions to define social mobility (Malek, 2009: 185). Sorokin defines social mobility as the movement of the individual within the social space (Tonekaboni, 2013: 4). Social mobility appears in many ways. Including inter- and intra-generational mobility, job mobility and:

- Intergenerational mobility: It is a type of mobility that children receive above or below the social base of their parents.

- Intra-generational mobility: A change in the social status of an individual or group in the same generation.

- Mobility: A change in the social status of a group or a group of individuals that usually occurs in major social upheavals such as political and social revolutions.

B) External and internal inequalities and social mobility in society: External inequalities were first raised by Durkheim. Durkheim distinguishes two types of inequality. Internal inequality and external inequality. External inequalities apply to the individual on the basis of birth conditions. Like her family's class background, their income, and their social base. On the contrary, internal inequalities are based on the needs of social divisions and on the basis of individual talents (Chalabi, 1996: 192). Internal inequalities are more specific to industrial societies, and external inequalities refer to pre-industrial societies. Our research focuses on external inequality in women's social mobility. Because the society we surveyed during this period imposed many external inequalities on women.

C) Social Mobility Factors: There are several factors that contribute to social mobility, some of which are titled.

- Job and job changes

- $\quad$ Ethnicity and religion

- Social Transformation

- Social communication

- Educational Facilities

- Family size

- $\quad$ Gender (Rasekhi Bakhshaysh, 2016: 72)

D) Effects and Results of Social Mobility: Social mobility in different societies has a variety of reflections, but with some neglect, one can have a commonality between these consequences:

- One of the effects of social mobility is to increase social and economic efficiency.

- Social mobility destabilizes social stratification. In a society with high social mobility, members, 
strata, and social bases change regularly.

- Social mobility has a direct impact on political organizations and parties in society (Matras, 1948: 39).

\section{Research Background}

There has been no research on the subject before, but research has been carried out close to our goal. Among them are Zahra Ghaffari and Mansour Haghighat's research on social mobility based on Bourdieu's view of Gorgan's 30-54-year-olds (Ghaffari and Haghighat, sophomore year). Or refer to the research by Abolghasem Rasekhi, who was published at the 10th Congress of Progressives, which focuses on social mobility and the factors affecting it, relying on the Iranian people (Rasekhi Bakhshaysh, 75-66). Also refer to the article by Samad Kalantari and Mohammad Salman Ghaemizadeh, about social mobility with a case study of Hamadan, published in the Journal of Sociology in Winter 2002 (Kalantari and Ghaemizadeh, 76-100). And finally, Shirin Mahdavi's article should be mentioned, which was published in October 1994 in a study entitled Social Mobility in the Qajar Period in the Journal of Political-Economic Information (Mahdavi, 99-85). There is a lot of research into the concept of social mobility, but research that specifically addresses this issue has not been done so far.

As mentioned earlier, during this period many changes were made in the country and social strata were transformed. Women were the most important group affected by these changes in adolescence. Although the discovery of the veil took place in 1935, civil society activists and activists have long sought to establish the context. The Taj al-Saltanah has cited hijab as the root of many problems in his material. He argued that a man's meager earnings from the working class would never meet the needs of his family. Especially since many of the members of this family were usually women. The hijab is removed and women can be employed in various professions, can earn a decent living, and the whole family can live in comfort and honor (Shuster, 51). In her excursions, Taj al-Saltanah sees the effects of the lack of veil and openness of women in doing and participating in economic affairs, and in some of her memoirs she describes it as:

While traveling in Tabriz, across the road and in the countryside, I saw men and women working together without a veil. In all one in ten, there is no unemployed person. One servant wanted to take me on the road; none of the farmers came and sold their free wild life (Atehadiyh, 1982: 101).

Studying women in the world of knowledge was another case that opened the door for women to work and social activities. Prior to the Pahlavi era, girls and women generally did not attend school or, if there were any exceptions, girls were aristocrats and princes who did not generally see the need to participate in economic affairs. The absence of girls in the educational environment was influenced by two family and social problems. Family bias and discrimination and lack of intellectual and social development in the Qajar period. The number of female students in the year 1301 coincided with the coming of Reza Shah 7592 people that in 1941, the end of Reza Shah's government reached 88195 and this number in 1934, a year before the discovery of the veil 45542 (Menashri, 1992: 169) This figure shows that the number of female students in the First Pahlavi government has almost tripled. This growing trend continued under the reign of Mohammad Reza Shah, with many women attending primary, secondary, and higher education, earning high degrees, and entering into economic activities in support of their education.

\section{Women's economic activity in nomadic and rural communities}

Large-scale agriculture for the purpose of commerce is one of the things that are naturally included in the Jirga of economic activity. The role of women in this field, though not as bold, is found in texts and documents. For example, during a series of documents on non-payment of taxes on opium in Fasa, a woman is also mentioned as belonging to the same farmer who, incidentally, is taxed and her products released (National Library Documents, Document No. 230 / 2721).

After the reign of Qajar, with the beginning of Reza Shah's rule, the first attempt to consolidate central power was to suppress tribes and tribes that were expanding power and extermination in Iran. This move from the north to the south, with the presence of the Shah, was so practiced that it also changed the color and smell of nomadic and nomadic millennia in Iran. The Khanin were forcibly settled in cities, some were exiled and some were executed. From Qashqai Turks to Bakhtiari and Sheikh Khazel in Khuzestan. As the process progressed, bans were soon banned and nationwide efforts to resettle in and around the city began. The general proclamation also forced all the tribes to abandon the tribes until a certain date.

In addition to leveraging the pressure to integrate the nomads, a historical factor also came to the peasants to push them out of their traditional form. Migration In the present century, more than all of Iran's history, migration has played a role in the demise of the tribal and tribal structures. The immigration of Bandar Abbas 
to Fars and Khuzestan in the early 1930s was a major concern for the then government. From this period there has been no clear correspondence documenting the worsening immigration situation. Often hungry and poor in Bandar Abbas, they were moving to oil-rich and industrialized areas to find a job and provide for their basic needs. The outlook for these people is clear in the letter from Fars Inspector General Brigadier General Amir Parviz to the Fars governor:

\section{Dear Governor of Seventh Province, dated 1951/12/20}

Respectfully 220/30, 51/12/20 states: Bandar Abbas is an independent and separate area of Fars and the best way to prevent the emigration of residents is to prevent and prevent Bandar Abbas himself and its functions. But the livelihoods and livelihoods of life where there are limits are not supposed to be prevented as they deserve. I have personally observed in my travels around the world that these people are moving in the bitter, hungry, miserable, miserable condition that I can expressly lack, the basic conditions of living in these bare, desolate deserts. Be that as it may, the heart of every stone is watered, with the extent of the area and no means of containment within that boundary impossible and fundamental action must be taken in this regard (Documents on Internal Migration, 41).

The migration of people who lack specialization and expertise, from societies that do not have a variety of jobs, to a source of income and to various occupations, has little impact on economic growth in the country. Immigrants from areas such as Bandar Abbas to Shiraz were not unintentionally carriers of the profession that boosted the Persian economy. Port women were also generally housewives who, in their most active form, had learned searelated tasks such as cleaning and drying fish and such as mat-making, which were not applicable in Fars and Shiraz.

The same issue of widespread migrations to Fars and Khuzestan and the causes of these migrations is a clear indication of the stagnation of economic activity in those areas for both men and women. Women in parts of Minab and Bandar Abbas were able to spend their life on the mat by exporting it to large cities such as Shiraz. But the subject of poverty in the major areas of Bandar Abbas until the early 1960s was that the same small rural handicrafts continued to decline until little by little, with the boom in business and commerce and the resurgence of Bandar Abbas, as an important region, life was restored to its people. The economic activities of rural women in the post-Qajar period until the early 1930s were strongly influenced by these migrations. Economic activity in the countryside and among the tribes did not earn much, and many who thought that by migrating to the city could prosper or find a better job, they had lost little rural and nomadic economic activity, and in the city, They generally worked in jobs such as labor, gardening, grocery, homestead, counter, prostitution, and so on.

In general, no new profession or activity was produced by the villagers and tribes during the Pahlavi period, and what was also a continuation of the decline of pre-Pahlavi works. In the Persian Gulf, women used to clean cheap fish and shrimp, as in the past. The apples were busy. In the rice fields in areas such as Mamasani, Biza, Kamfiriz and Marvdasht, young girls were always used in the cultivation phase. Such activities were cross-sectional and related to the time of planting or harvesting. So many women in need for the rest of the year were either unemployed or doing laundry and housework. The situation was much worse in the southern parts of Iran, especially in the Persian Gulf, so that some of those areas became deserted due to the destruction of agricultural land and the lack of water. In a detailed report from different parts of the Persian Gulf in 1945, Razmara writes: Considering the relevant statistics, we find that about 26,000 inhabitants of Iran are concentrated in the southern islands of the country and occupy a relatively large space at sea (with 126,000 Bahraini islands). Although these islands are remarkable in size, they are not economically valuable, as they are not well developed due to the lack of fresh water, the lack of agricultural and agricultural land, so that even for living and livelihoods. The current ones also have to provide their own grain from outside. Among the islands of the Persian Gulf, the only islands that are susceptible are Kish Island, whose land is relatively better and has more agricultural and agricultural potential. So, these islands are not agricultural in importance and even need to be supplied from the adjacent coasts. The lives of men in these areas are provided by pearl fishing, fishing, boating and boating. Since these parts are also small and insignificant compared to the past, so the livelihoods of the inhabitants are greatly impaired, and as a result they have largely migrated north and south (Razmara, 1945: 117). The removal of nomadism and the tendency for homogeneity for the Iranian nomads has also been better in areas economically perhaps the most positive. Il Inanloo According to local knowledge, the Inanloo came to Iran in the Mongol era and the Baharloo in the Seljuk era and were divided into the Bollordi, Slamloo, Bayat, Ghore. In 1916, before the reign of Reza Shah, they left the country to live in cotton, opium and tobacco farming and made a living there (Vaez, 2009: 165).

The shift in nomadic and migrant women's employment has led to a downward social movement in most cases and an upward social mobility in some areas. So the nomadic women, moving to the city, lost their previous social 
status and diminished their jobs, as mentioned. But in a general sense, this migration can be seen as a ground for the upward social mobility of nomadic women, their later generations. Although emigration to the city, although their first generation had disadvantages and difficulties, in the next generations due to access to educational and welfare facilities, their growth in society and their vertical social mobility.

\section{Women's economic activities in urban communities}

Urban communities as the source of knowledge education naturally have the advantage of rural communities in this field. With the advent of Pahlavi rule and the generalization and expansion of knowledge gained, women have become more open to this new field. With the acquisition of knowledge, and interest in the field, a formal job as a teacher and secretary entered the cultural market, which also increased the number of enthusiasts each year. In addition to the income that teachers received, it also added a social dimension to the personality. For this reason, in addition to meeting the financial need, there was also a cultural and personality competition among individuals to achieve this job.

Entering the Qajar fanaticism, in which patriarchal and fanatical views of women were inflamed, we entered a new era in which we sought to position ourselves as a member of the progressive world by modeling on Western cultural and economic models. This comparative patterning began years before the discovery of the veil from France and England, and in the second decade of Pahlavi's rise to power in Turkey. After the discovery of the veil, women's activists sought far more cover to open the role of women than men in economics, politics, and culture. This can be seen in the remarks made by Ms. Shayesteh Sadegh, son of Mostashar al-Dawlah Sadegh in the Women's Association, which was published in a booklet in 1936. The rhetoric explicitly compares Iranian and Turkish women and undermines the freedom and participation of Turkish women in the face of the shortcomings and isolation of Iranian women. He then mentions occupations such as medicine, judging, the post and telegraph, etc. that there are several thousand women in Turkey (Sadegh, 1936: 113). The effect of Pahlavi rule changes on women is mainly due to 1935 . The sabotage of literate and literate women gradually made Iranian women find themselves in the men's jirga. The start of propaganda and the publication of Western features in the publications can hardly be considered as one of the most important factors in women's growth. Women who were literate and had little knowledge of the language were translating news and stories from Western women to bring more Iranian women into the fold. Of course, women began translating articles and publishing them in publications from the late Qajar period and matured into the Pahlavi era.

During this time, women have always been working under the pseudonym to make sure that this culture is not stopped so that the country's economic, social and cultural ship will once again accommodate women and move across the country's rivers. Highly read and interesting translations drawn from Quarterly periodicals such as "Pars" and "Pars" and Farsi's will in the Pahlavi period. Translates and publishes an article titled "The Importance of Jobs in America" (Pars Newspaper, February 4, 2008). This article, which was deliberate in its selection and translation, first highlights the importance of the subject and then goes into women's jobs and the presence of women in the American economy. The publication of this article in a well-known and important journal such as Pars in Shiraz and the south of the country naturally created a spark in the minds of women who have been through the Qajar era and are openly waiting for modernity and modernity. In June 1925, Ms. Jaleh Alp, the daughter of a well-known and educated militant in Shirazi, gave a detailed lecture at the Iranian-British Cultural Association titled "Women's Participation in the World" on various topics such as the history of women's participation. In the community, women in the military arena, women doctors and nurses, women in the industry and women volunteering. On this day, the main audience and most of the participants were women, and a few days later, the text of her lecture was published in five consecutive issues in the Fars Newspaper (Fars Newspaper, June 1946). This was in spite of his increasingly progressive, scholarly and motivating ideas in society. Thus, during this period, we witnessed the rise of women in the social arena and the rise of upward social mobility in the class. This began during the first Pahlavi period and intensified during the second Pahlavi period. We will now refer to some of this social presence and mobility.

\section{Culture and Economics}

With the reign of Reza Shah, the country had a different color in education. The new way of building schools, practically begun in the mid-first decade of the present century, enabled Bobby to enter the field as well. The first Farsi girls' school in the Pahlavi era should be called the Aftiyya School, which was actually the beginning of the final years of Qajar life. Cheers of Sakineh Efat Beghazi, mother of the poet Dr. Hamidi in 1960 AH. AH, with the encouragement of the late Rahmat the Head of Education, established a four-grade school for girls in his home. But the establishment of that school had created an emotional crowd that was eliminated with the support of education and the perseverance of its principal.

In the year 1924, due to the seriousness of Haj Seyyed Mohammad Soltani (Sultan al-Alma), he became head of the Persian school of education at the public school, holding fifth and sixth grades, and in 1925, 12 volunteers took the final exams in June. This was the first time girls' school volunteers took the final exams (Emdad, 2006: 331). 
With the expansion of this school and the increase in the number of students, the need for an assistant as a teacher and principal naturally increased. At the beginning of the academic year 1928-1929 the first grade of secondary school and by the end of the academic year 1932-1933 the fifth grade was held at that school (Same). In the year 1927 in Estahban, a class called Miss Hemmat School was established under the management of Mrs. Betul Wareh with 19 pupils from the Fars Cultural Department. This elementary school gradually became six classes (Ibid, 642).

In September 1928, the Fars Education Office established a school for girls under the leadership of Mrs. Fatemeh Begum Salami in the Masli neighborhood. Determined. The number of students in that school was over 75 per year (Same, 655). The Fars Education Office established a girls' school in Jahrom in 1928 under the leadership of Mrs. Esmat al-Sadat Korey. The school was transformed into three classes in the academic year 1936-37 and was managed by Ms. Zahra Alaviyeh Yoohi with two teachers and 37 students (Ibid, 645).

In 1928, the Fars Education Office established a school for girls called Zenahari in Abadeh, and gradually added to its classes, and in the school year 1936-37, it had sixteen elementary schools $(114,638)$. Unfortunately, the exact number of staff and teachers at the school, all naturally female, is unknown. In the year 1930 Solar, a person named Talat Khan Abadei, founded a two-grade girls' school in Abadeh and gradually added four classes to form a six-grade primary school but was dissolved in 1935 (the same). According to statistics compiled by the Adaptation Bureau for the academic year 1931-1932, there were six schools in Shiraz where 48 male and 12 female teachers were employed (Adaptation Bureau for the academic year 1931: 9). The Larestan Girls' State Primary School was established by the Fars Education Department in three classes in 1934-35, and was administered by Ms Resam Pushoon and two other teachers with 45 students in 1335-36(Emdad, Ibid, 653).

In 1934, based on the available documents (Archives of National Library and Documentation Organization, no. 98-293-4231), correspondence regarding the establishment of a girls' school in Shiraz was made. The head of the school was a woman named Alajard, who did not know exactly what her nationality was. But the school seems to have been set up in 1312 and correspondence is set to launch its second round. Its location and number of students and teachers are not known precisely, but in any quality and quantity, there may have been some female teachers or maids. The following document is the latest in a series of documents that actually authorize the school to operate in the second round, issued on September 26, 1934. In Nairiz and Abadeh there are reports of girls' schools being established along with the recruitment of female staff. During this period, there was a stir among Farsi women to study and to choose teaching jobs, especially among urban women, which helped to promote their social status.

\section{Decoration}

One of the jobs that became popular in Iran after the discovery of the veil was hairdressing, which had previously been done in homes and in a very unprofessional way. With the discovery of the veil and the launch of publicity campaigns, which made the western and free form of women more popular, the attitudes and needs of women began to shift. Farsi women were no exception, and with the choice of a hairdresser, sought to improve their social status previously held by the man as a housewife or "sex object."

There was no evidence from the first years of the establishment of a hairdresser in Fars, but in a public announcement in the Pars newspaper, this documentary and despite the usual type of announcement, it can be assumed that several years have passed since such a job. The statement reads: "A golden earring of one of the ladies is left in the process of curling her head. The owner can receive it by giving an address. Hairdresser of Lady Pishdadian" (Pars Newspaper, March 18, 1949). In addition to hair styling for a variety of day-to-day hairstyles, nail decoration and possibly facial makeup have also entered Iran in the early Pahlavi period. In the text of a report from the Shiraz Lawyer's Market, quoted in the Pars newspaper in 1942, it refers to a woman who had her nails manicured (Pars Newspaper, October 23, 2011). So it's definitely not a hairdresser job, a casual job for anyone to get into with enthusiasm and need without training.

Hairdressing for women, especially since the release of the veil and the appearance of the hair, had a lot of prosperity, along with facial and body adornment. Due to its importance, especially for the noble or wealthy family, it also provided the hairdresser with a good income, so many men and women would later take up the job. Add more jobs to the country.

\section{Government employees}

Most women in Fars culture departments may have used women as employees, but the documents and writings of this period have only briefly referred to employees of small-town culture departments. Ms. Houri Tajbakhsh, for example, has been working as an education inspector in Abadeh's Cultural Department in 1328-1989 (Fars Cultural Yearbook, 75). On the same side, the name of Lady Mahin Ban is also mentioned in the Jahrom Culture Bureau, which was its technical inspector in 1950 (Jahrom Cultural and Sports Yearbook, 50).

In the Fars Yearbook, while praising the employees of Abadeh Cultural Bureau who have agreed to spend one percent of their monthly salary on building the culture building, the names of the staff include: Lady Pourmazeh, Lady Malek Soltani, Lady Iran and Manijeh Riahi, Lady Zari Tajbakhsh, Talat Chubineh Dana, Fatemeh Khalili, 
Tabandeh and Hakimeh Arabi, Ezat Judah, Honorable Masrour, Lady Blessed Shariatmadari, Akhtar Firouzi (Yearbook of Fars Culture, 84). After the phone arrived in Iran, the industry gradually entered the big cities. In Shiraz, by early 1922, all telecommunication or telephone workers were men, and by the middle of this year, Shiraz women had entered the telephone as employees. Their name, amount and type of work did not provide any evidence. But they are thought to have worked in the telecommunications sector. In a short piece in the Pars newspaper, their activity is reported in a humiliating way to women:

\section{Strike the housework staff}

This morning the city phones were out of order. I think the housekeepers have all gone on strike because neither the center nor, as our friend Mr. Tully, the "Mrs. Center" would answer, would answer. It is as if the hiring of the lady did not improve the housekeeping business, and even increased the cause and has caused more discontent among the housekeepers. We expect the head of the telephone company and their male and female employees to complete their task and the people as soon as possible (Pars Newspaper, August 3, 1943). The use of women in telephones may have been imitated by Britain and the United States because they used men in those countries at first, but after some problems, particularly with regard to telephony conflicts with subscribers, they used women with even greater patience. And they had a pleasant voice and a kind voice in the word.

\section{Medical and Medical Services}

With the rise of the Pahlavi government and the coronation of Reza Shah, medical services and health promotion were expanded and, with the help of Western science, tried to abolish the traditional and dangerous methods of treating the patient. In 1928, when the School of Medicine and Compatibility and Schooling Regulations were published, midwives were also required to undergo modern courses in order to obtain a legal work permit.

With the establishment of the University of Tehran, in 1933, according to the necessity of the community, they started the first faculty with the subject "Medicine" to educate the new generation of physicians and nurses with Western knowledge and Eastern traditions. The Qajar Period and earlier, all relied on traditional medicine for medical science, and, except for the experience of new plants, did not bring any particular innovations in improving the treatment. The disease was highly prevalent among the people and most of the deaths were due to the oftencontagious diseases. In a quarterly report on the city of Tehran in 1925, the legacy of the Qajar era and the general state of the country can be well understood and compared to other cities. In the first quarter of this year, a total of 1053 people died, of which 11 died as a result of aging and 4 committed suicide, but the rest died entirely from a variety of illnesses such as tuberculosis, cancer, smallpox, measles, etc. (Baldiyeh Magazine, No. 23, 8)

The first Fars clinic of the Imperial Plan was the one in Lar, which was opened on July 15, 1948. Thereafter, the Abadshapur clinic was in the city of Khafr, which was opened to the public on October 14, 1948. By 1929, Darab's clinics were in operation on December 18, 1929, Arsanjan III in December 1927, Nourabad Mamasani on December 18, 1928, and Awes on December 20, 1929 (10-year journal of the Imperial Social Service Organization, 10).

In all these centers, from the first day, in addition to employing non-Iranian physicians, they also employed women as nurses, gradually increasing in number and benefiting in the later years from Iranian midwives. In the 20s, what is notable is the use of women as midwives or nurses. The inclusion of women in Fars clinics and hospitals has been at the forefront of the process, with the trend of bringing women into the medical field in the coming years and further education. Since every movement requires far-reaching prerequisites, the lack of a female physician in Fars in the early decades of Pahlavi does not seem so strange. If women had not been in the nursing and midwifery realms, it would have been difficult and even impossible to accept them as traditional physicians. Dr. Christ Agah set up a hospital in Shiraz in 1942, which employs women in nursing at the initial announcement of the request for force (Pars Newspaper, March 13, 1942).

Until 1949, there was no information on the existence of a woman as a physician in Fars. The physician in this section is the women who came up with modern education, not traditional therapists. With the establishment of the Organization of Iranian Jewish Women in July 1947 and the establishment of various branches of this organization in areas of Iran, several job opportunities were provided for often Jewish women in the country. The organization was initially set up by Parvin Hakim and Iran Navi. But it gradually expanded and established branches in cities such as Tehran, Isfahan, Ahvaz, Arak, and so on. A branch in Shiraz was also established in the south of Iran, which reportedly named Lady Zarrin Farivar as a guest at a seminar (Iranian Jewish Women's Bulletin, 21). In the 1951s, there was an ad in the Pool newspaper in an ad that was jointly run by a man and a woman. Dr. Hashmi, who is a leading scientist in obstetrics and gynecology. This is perhaps the first time a woman has entered the field of modern medicine (Pool Newspaper, July 10, 1985). Of course, except for the medical jobs that Persian women entered the field too late in the period, they had a hand in other medical careers such as midwifery and midwifery, and reports appeared in newspaper pages in the 1941s and 1951s. 


\section{Conclusion}

As we have seen, during this period in Iran, there was an uproar between the class of infirmaries for entering into social activities and promoting our social dignity. Prior to this period, Iranian women did not play an important role in society and in economic activities. But during this period, with the changes that took place in Iranian society, there was a significant upward movement of vertical social mobility between Iranian and Persian women. Women were not allowed to leave their homes before that date, but after that, women entered the community, received education, and gained many jobs. Most of the growth in social mobility in contemporary history belongs to this period. During this period, women gradually and slowly entered the community, but this momentum intensified during the reign of Mohammad Reza Shah. Of course, after the 53's and 61's and 71's, Fars women had a significant presence in commercial and commercial activities, which we are not aware of. It should be noted, of course, that these changes were unintentional and that the global atmosphere of the twentieth century and women's liberation movements had exerted additional social pressure on statesmen. They had no choice but to accept these changes and to empower women and not to give the Pahlavi dynasty a more than real role. However, according to the definitions we have put in the theoretical framework, social mobility has grown dramatically and vertically in our time period. This vertical social mobility can be seen in different layers of women, even in traditional segments. Prior to that, women only had a role in the interior of their homes, but after that they turned to jobs such as hairdressing, teaching, nursing and medical care, and in some cases, government employees, indicating widespread vertical mobility and in some areas mobility. We have seen a horizon where few educated women have improved their social status before the breeze. As a result, widespread social mobility occurred during this time period, and this was mainly vertical social mobility.

\section{BIBLIOGRAPHIC REFERENCES}

Adibzadeh, Majid (2013). The Rise of Rationalization in the Rise of Modern. Iran, Tehran. Ghoghnos.

Aryanpour, Manouchehr et al. (2006). English to Persian Culture. Tehran. Computer World.

Chalabi, Massoud (2010). Sociology of Order. Tehran. Ney.

Emdad, Hassan (2006). History of Education in Fars, Shiraz. Navid.

Etehadiyeh, Mansoura (2002). Memories of the Taj al-Saltanah. Tehran. Iranian History Publishing.

Malek, Hassan (2009). Sociology of Social Cases and Inequalities. Tehran. Payame Noor University Press.

Menashri, David (1992). Education and the Making of Modern Iran, Cornell University press.

Milespot, Arthur (1976). The American Mission in Iran. Translated by Hossein Abotrabian. Tehran. The Message.

Presidential Book and Document Center (2011). Documents on Internal Migration in Iran.

Rasekhi Bakhshayesh, Ahmad (2016). Social Mobility and its Factors (Based on Iranian Society). Tehran. Proceedings of the 10th Congress of Progress Pioneers.

Sadegh, Shayesteh (1936). Women in Iran and Turkey. Tehran. Armaghan.

Salah, Mehdi (2005). Hijab Discovery, Contexts, Consequences and Responses. Tehran. Institute for Political Studies and Research.

Shuster, Morgan (2005). Women's Committees and the Origins of the Women's Movement in Iran. Translated by Sarah Judge, Idle.

Taghavi, Nematollah (2010). Rural Sociology. Tehran. Payame Noor University Press.

Tonekaboni, Hamid (1998). Significant Obstacles to Social Mobility in the Development Process (Asian Countries). Asian Studies Quarterly, vol 4 and 5.

Vaez, Nafiseh (2009). The Tribal Politics of the First Pahlavi State. Tehran. Iranian Publication.

\section{Journals and newspapers}

Pars newspaper, Shiraz, 1941 - 1952.

Yearbook of Fars Education, 1936.

Jahrom Culture and Sports Anniversary Calendar, Jahrom Culture Office, 1950.

Baladiyah Journal, 4th Year, No. 8, September 1925.

10-year Bulletin of the Imperial Organization of Social Services, 1947 to 1957.

Estakhr Journal, 1951.

Alam-e- Neswan Magazine, July 1927. 